\title{
STUDI PERILAKU PADA SAMBUNGAN RECTANGULAR CONCRETE FILLED TUBES (RCFT) DENGAN METODE FINITE ELEMENT
}

\author{
Cintantya Budi Casita ${ }^{a}$ dan Budi Suswanto
}

\begin{abstract}
This research presents the result of two rectangular filled tube column-to-beam connections under cyclic loading using finite element analysis. Connections of all two models were using weld connection and shear tab attached to beam webs. In this study, 2 models were made: RR-1 and RB-2, which are RCFT connection with RBS and RCFT connection without RBS. This study is conducted to learn, the advantages of RCFT connection with RBS against RCFT connection without RBS. The analysis results observed that cyclic performance of the RBS moment connection was much superior to the connection without RBS. The highest regions of stress occur in vicinity of beam bottom flange near column face for connection without RBS. For connection with RBS, the highest regions of stress occur in reduced beam section of the beam.
\end{abstract}

Keywords: Concrete filled tubes; Connection; Finite element; Monotonic load; Reduced beam section;

Abstrak : Studi ini membahas tentang perilaku dari dua tipe sambungan kolom Rectangular Concrete Filled Tubes (RCFT) dengan balok baja saat diberi beban monotonik dengan menggunakan software berbasis metode elemen hingga. Pemodelan ini meliputi pemodelan sambungan RCFT dengan jenis sambungan las menggunakan shear tab. Terdapat 2 tipe sambungan yang meliputi sambungan RCFT dengan dan tanpa Reduced Beam Sections (RBS), yaitu model sambungan NRBS (Non RBS) dan WRBS (With RBS). Hasil yang diperoleh dari studi ini menunjukkan bahwa sambungan dengan menggunakan RBS memiliki performa yang lebih baik. Karena dengan adanya RBS, letak sendi plastis dapat direncanakan dan dapat dipastikan bahwa sendi plastis pertama terjadi lebih dulu dan dapat menjamin bahwa sendi plastis terbentuk di daerah RBS yang letaknya jauh dari daerah kolom.

Kata Kunci: Beban monotonk; Concrete filled tubes; Finite element; Reduced beam section; Sambungan.

\section{PENDAHULUAN}

Runtuhnya bangunan saat terjadi gempa akan menimpa orang didalamnya sehingga dapat menimbulkan luka-luka bahkan kematian. Maka dari itu, diperlukan struktur bangunan tahan gempa, sehingga jumlah korban jiwa akibat adanya gempa dapat diminimalkan. Contohnya, kejadian gempa Northridge, California (1994) dan gempa Kobe, Jepang (1995) yang menunjukkan bahwa runtuhnya struktur-struktur baja saat itu disebabkan oleh kegagalan pada sambungan.

Struktur komposit baja-beton telah banyak digunakan pada berbagai macam konstruksi bangunan. Penggunaan baja komposit memungkinkan pemanfaatan seluruh penampang dalam menerima beban, karena adanya interaksi antara komponen struktur baja dan beton yang karakteristik dasar masing-masing bahan dimanfaatkan secara optimal, sehingga didapat kinerja struktur yang lebih efektif dalam meningkatkan kapasitas pembebanan dan kekakuan bangunan. [1]

Pengurangan sebagian penampang sayap balok dengan RBS (Reduced Beam Section) bertujuan untuk menjamin terjadinya sendi plastis lebih dulu di daerah RBS yang letaknya jauh dari daerah kolom. [2]

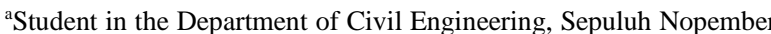
Institute of Technology (ITS), ITS Campus, Sukolilo, Surabaya 60111, Indonesia. Email: cintantya.budi15@mhs.ce.its.ac.id

${ }^{b}$ Lecturer in the Department of Civil Engineering, Sepuluh Nopember Institute of Technology (ITS), ITS Campus, Sukolilo, Surabaya 60111, Indonesia. Email: budi_suswanto@ce.its.ac.id

Note. The manuscript for this paper was submitted for review and possible publication on January 01, 2017. This paper is part of the ITS Journal of Civil Engineering, Vol. 32, No. 1, May 2017. (C) ITS Journal of Civil Engineering, ISSN 2579-9029/2017.
Dengan adanya studi ini diharapkan pemodelan sambungan-sambungan kolom CFT - balok baja yang memenuhi syarat dapat diperoleh.

\section{KEPENTINGAN RISET}

Penggunaan elemen struktur komposit seperti kolom CFT akan memberikan beberapa keuntungan, antara lain: kekuatan per satuan luas lebih besar dibanding kolom konvensional beton bertulang sehingga dimensi kolom bisa lebih kecil, tidak memerlukan bekisting lagi untuk pengecoran beton, kombinasi kekuatan dari dua material baja dan beton membuat kolom CFT cocok untuk bangunan tingkat tinggi [3]. Namun, penggunaan struktur CFT ini masih terbatas karena kurangnya pengalaman pelaksanaan dan kerumitan pada sambungan. [4]

\section{METODOLOGI}

\section{Reduced Beam Section (RBS)}

Reduced Beam Section (RBS) merupakan sebuah metode pengurangan luasan sayap dari penampang balok dengan jarak tertentu dari tumpuan, sehingga memaksa sendi plastis agar terjadi pada bagian RBS yang berada jauh dari kolom [5]. Sambungan tanpa menggunakan RBS memiliki performa yang kurang baik dibanding sambungan menggunakan RBS. Hal ini disebabkan retak yang muncul pada bagian sayap balok. [6]

Konsep ini semakin berkembang setelah terjadinya gempa Northridge dan gempa Kobe. Terdapat lima tipe RBS, yaitu Straight Cut RBS, Drilled Holes RBS (Straight), Drilled Holes RBS (Zig-zag), Tapered Cut $R B S$, dan Radius Cut RBS [7]. Untuk lebih jelasnya dapat dilihat pada Gambar 1. 

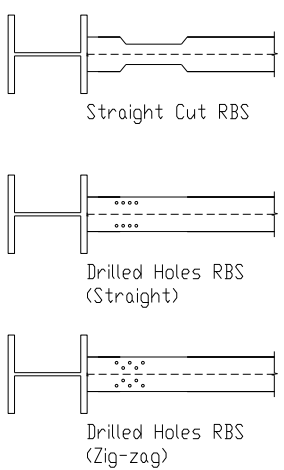
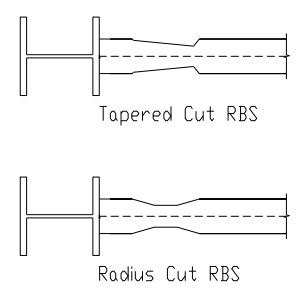

Radius Cut RBS

Gambar 1. Macam tipe pada Reduced Beam Section (RBS)
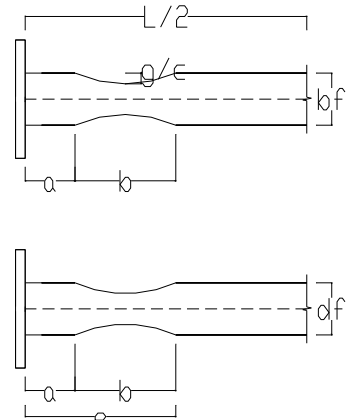

Gambar 2. Detail Geometri Reduced Beam Section (RBS)

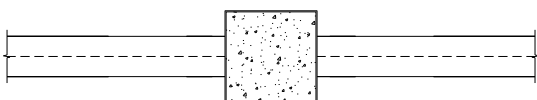

SIDE 2-2
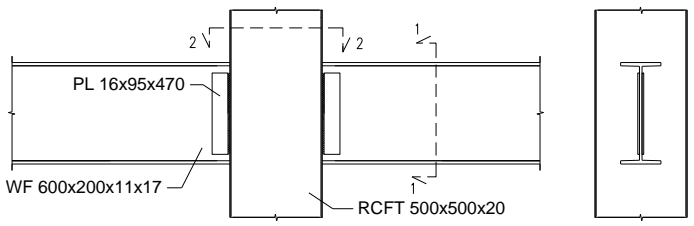

SIDE 1-1

Gambar 3. Detail Sambungan Antara Kolom RCFT - Balok WF (NRBS)

Desain sambungan RBS mengacu pada peraturan American Institute of Steel Construction (ANSI/AISC) 341-10,358-10,360-10 dan AISC Steel Design Guide Series-13 [8-11]. Detail geomteri RBS dapat dilihat pada Gambar 2 dan Tabel 1.

\section{Model Sambungan}

Studi analisis ini meliputi pemodelan sambungan dengan program bantu finite element dengan tujuan untuk mendapatkan parameter yang mempengaruhi perilaku sambungan. Tabel 2 menyajikan detail sambungan yang digunakan pada pemodelan. Terdapat 2 tipe sambungan: NRBS dan WRBS, yang meliputi pemodelan sambungan RCFT dengan jenis sambungan las menggunakan shear tab di bagian balok dengan RBS (WRBS) dan tanpa RBS (NRBS). Untuk lebih jelasnya dapat dilihat pada Gambar 3 dan Gambar 4. Kedua tipe sambungan tersebut diberi beban monotonik dengan menggunakan software berbasis metode elemen hingga, yaitu ABAQUS 6.14 .

\section{Material Properties}

Baja

Elastic properties pada baja meliputi Young Modulus E dan Poisson's ratio $v$, dimana digunakan nilai sebesar $200000 \mathrm{MPa}$ dan 0.3.

Untuk plastic properties, digunakan rumus teganganregangan [12]. Gambar 5 menunjukkan diagram tegangan-regangan material baja.

$$
\begin{aligned}
\varepsilon_{y} & =\frac{f y}{E s} \\
f s & =\varepsilon_{s} . E s
\end{aligned}
$$

Dengan persamaan diatas, dapat ditentukan nilai tegangan-regangan baja (fy $250 \mathrm{MPa}$ ). Untuk lebih jelasnya dapat dilihat pada Tabel 3.

Beton 

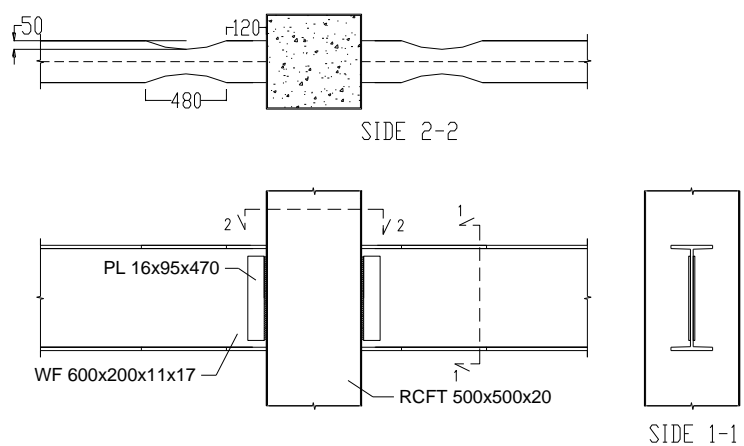

Gambar 4. Detail Sambungan Antara Kolom RCFT - Balok RBS (WRBS)

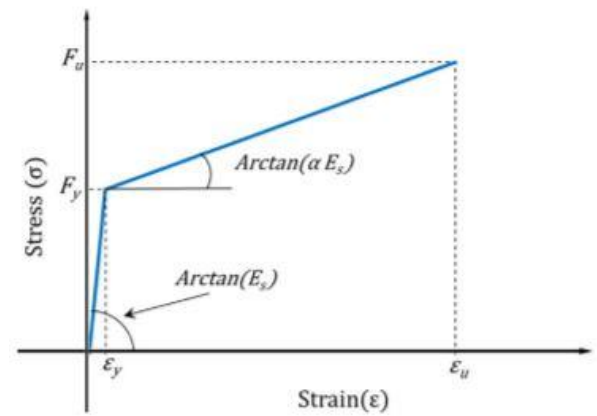

Gambar 5. Hubungan Tegangan-Regangan Baja
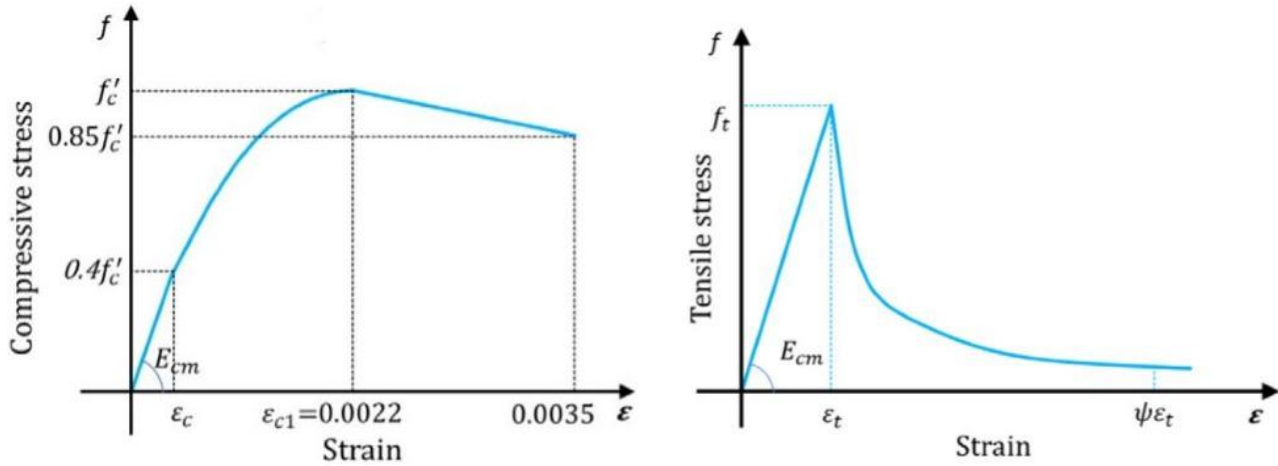

Gambar 6. Hubungan Tegangan-Regangan Beton akibat Gaya Tekan dan Tarik

Nilai modulus elastisitas pada beton dihitung dengan rumus: [13]

$$
E_{c}=w_{c}^{1.5} 0.043 \sqrt{f c^{\prime}}
$$

dengan, $\mathrm{w}_{\mathrm{c}}=2400 \mathrm{~kg} / \mathrm{m}^{3}$

Nilai rasio poisson beton sebesar 0.2.

Sifat plastis material beton pada pilihan property didefinisikan kedalam 3 kategori, yaitu plasticity, compressive behavior, dan tesile behavior.

Plasticity untuk material beton yang digunakan berdasarkan persamaan [14], sebagaimana yang ditunjukkan pada Tabel 4. Untuk compressive behavior dan tensile behavior pada beton, digunakan persamaan [12]. Hubungan tegangan-regangan dari compressive behavior dan tensile behavior pada material beton dapat dilihat pada Gambar 6.

Perumusan untuk compressive behavior pada material beton: [12]

$E c m=9.5\left(f^{\prime} c+8\right)^{\frac{1}{3}}, \mathrm{Ecm}(\mathrm{GPa})$ and f'c $(\mathrm{MPa})$ $n=\frac{\varepsilon_{c}}{\varepsilon_{c 1}}$, dengan $\varepsilon_{c 1}=0.0022$

$k=1.1 x \operatorname{Ecm} x \frac{\varepsilon_{c 1}}{f^{\prime} c}$

$f c=\left(\frac{k n-n^{2}}{1+(k-2) n}\right) f^{\prime} c$

Perumusan untuk tensile behavior pada material beton:

$$
\begin{aligned}
& f_{t}=0.623 \sqrt{f^{\prime} c} \\
& \varepsilon_{c r}=\frac{f r}{E c}
\end{aligned}
$$

Dengan persamaan diatas, dapat ditentukan nilai tegangan-regangan plastis beton akibat gaya tekan dan tarik. Nilai tegangan-regangan plastis beton akibat gaya tekan dan tarik yang digunakan dapat dilihat pada Tabel 5 dan Tabel 6. 

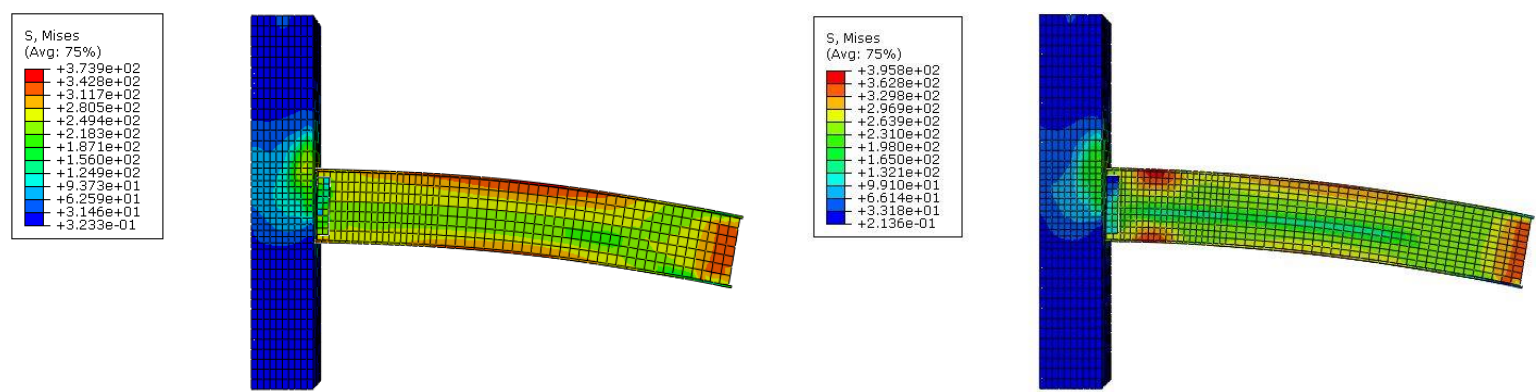

Gambar 7. Hasil S Mises pada Model Sambungan NRBS dan WRBS

Perpindahan vs Beban Dorong

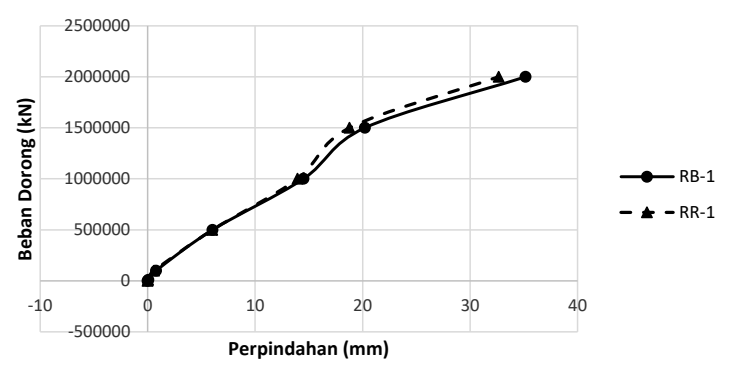

(a)

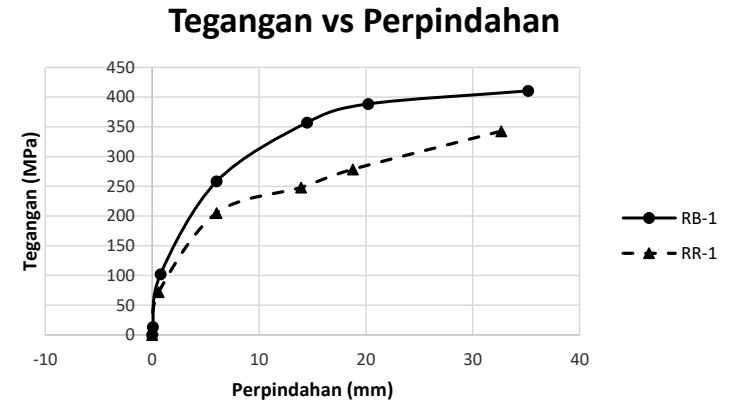

(b)

Gambar 8. Kurva yang Dihasilkan akibat Beban Monotonik

\section{Boundary Condition dan Pembebanan}

Boundary condition yang diterapkan pada model ini adalah perletakan sendi pada ujung kolom bagian bawah, dan perletakan yang ditahan kearah lateral pada ujung kolom bagian atas. Untuk bebannya, digunakan beban monotonik, yaitu dengan diberi beban sebesar $\mathrm{P}$ diujung balok tersebut. Besarnya nilai $\mathrm{P}$ yang digunakan dapat dilihat pada Tabel 7.

\section{ANALISA DAN PEMBAHASAN}

\section{Distribusi Tegangan}

Distribusi tegangan yang terjadi pada model sambungan tanpa RBS (NRBS) dan model sambungan dengan RBS (WRBS) dapat dilihat pada Gambar 7. Pada gambar tersebut, dapat dilihat bahwa model sambungan tanpa RBS (NRBS) mengalami leleh pertama sebesar $250.155 \mathrm{MPa}$ di daerah ujung sayap pada balok. Sedangkan pada model sambungan dengan RBS (WRBS) mengalami leleh pertama di daerah RBS sebesar 258.303 MPa.

\section{Perbandingan Perpindahan dan Tegangan}

Gambar 8 menyajikan diagram beban-perpindahan pada model sambungan NRBS dan WRBS. Dari Gambar 8(a), dapat disimpulkan bahwa besarnya beban berbanding lurus dengan perpindahan. Hal ini ditunjukkan oleh semakin besarnya nilai perpindahan seiring dengan bertambahnya beban. Pada model NRBS, leleh pertama terjadi pada saat mengalami perpindahan sebesar 14.041 $\mathrm{mm}$, dengan tegangan $250.155 \mathrm{MPa}$. Sedangkan pada model WRBS, leleh pertama juga terjadi pada saat mengalami perpindahan sebesar $6.029 \mathrm{~mm}$, dengan tegangan yang lebih besar yaitu $258.303 \mathrm{MPa}$. Untuk lebih jelasnya, dapat dilihat pada Gambar 8(b).

Dari kedua gambar tersebut, dapat disimpulkan bahwa model sambungan dengan RBS memiliki performa yang lebih baik jika dibandingkan dengan tanpa RBS. Karena dengan adanya RBS dapat menjamin bahwa sendi plastis terjadi lebih dulu di daerah RBS yang letaknya jauh dari daerah kolom.

\section{KESIMPULAN}

Dari hasil analisa yang telah dilakukan dalam penelitian ini, maka dapat diambil beberapa kesimpulan sebagai berikut:

1. Dengan adanya RBS, letak sendi plastis dapat direncanakan dan dapat dipastikan bahwa sendi plastis pertama terjadi lebih dulu dibandingkan tanpa RBS. RBS dapat menjamin bahwa sendi plastis terbentuk di daerah RBS yang letaknya jauh dari daerah kolom,

2. Besarnya beban yang diterima berbanding lurus dengan perpindahan. Hal ini ditunjukkan oleh semakin besarnya nilai perpindahan seiring dengan bertambahnya beban. Model sambungan WRBS memiliki nilai perpindahan sedikit lebih besar jika dibandingkan dengan model sambungan NRBS. 
Tabel 1. Detail Geometri Reduced Beam Section (RBS)

\begin{tabular}{c} 
AISC 358-05 \\
\hline$a=(0.5-0.75) b f$ \\
\hline$b=(0.65-0.85) d b$ \\
\hline $0.1 b f \leq c \leq 0.25 b f$ \\
\hline
\end{tabular}

Tabel 2. Rekapitulasi dari Masing-masing Tipe Sambungan

\begin{tabular}{ccccccc}
\hline Model & Column and Beam Size & Length & $\begin{array}{c}\text { fy } \\
\text { (MPa) }\end{array}$ & $\begin{array}{c}\text { fu } \\
\text { (MPa) }\end{array}$ & $\begin{array}{c}\text { fc' } \\
\text { (MPa) }\end{array}$ \\
\hline \multirow{2}{*}{ RW-1 } & Column & RCFT 500x500x20 & 3000 & & & \\
& Beam & WF 600x200x11x17 & 3500 & 250 & 410 & 30 \\
\multirow{2}{*}{ NRBS } & Column & RCFT 500x500x20 & 3000 & & & \\
& Beam & WF 600x200x11x17 & 3500 & 250 & 410 & 30 \\
\hline
\end{tabular}

Tabel 3. Nilai Tegangan-Regangan Baja (fy $250 \mathrm{MPa}$ )

\begin{tabular}{ccc}
$\begin{array}{c}\text { Tegangan } \\
\text { (MPa) }\end{array}$ & Regangan & $\begin{array}{c}\text { Regangan } \\
\text { Inelastik }\end{array}$ \\
\hline 0 & 0 & \\
250 & 0.00125 & 0 \\
410 & 0.2 & 0.19875 \\
\hline
\end{tabular}

Tabel 4. Plasticity Material Beton

\begin{tabular}{ccccc}
\hline $\begin{array}{c}\text { Dilatation } \\
\text { Angel }\end{array}$ & Eccentricity & fb0/fc & K & $\begin{array}{c}\text { Viscosity } \\
\text { Parameter }\end{array}$ \\
\hline 38 & 1 & 1.12 & 0.666 & 0 \\
\hline
\end{tabular}

\section{DAFTAR PUSTAKA}

[1] Elremaily A.; Azizinamini A., "Experimental Behavior of Steel Beam to CFT Column Connections", Journal of Constructional Steel Research, 2001, pp. 1099-1119.

[2] Kulkarni S. A.; Vesmawala G., "Study of Steel Moment Connection with and without Reduced Beam Section", Case Studies in Structural Engineering, 2014, pp. 26-31.

[3] Cheng C. T.; Chung I. J., "Seismic Performance of Steel Beams to Concrete-Filled Steel Tubular Column Connections", Journal of Constructional Research, 2003, 59(3): 405-26.

[4] Schneider S.P.; Alostaz Y. M., "Experimental Behavior Connections to Concrete Filled Steel Tubes", Journal of Constructional Research, 1998, 45(3): 321-52.

[5] Rahnavard R.; Hassanipour A., "Analytical Study on New Types of Reduced Beam Section Momen
Connections Affecting Cyclic Behavior", Case Studies in Structural Engineering, 2015, pp. 33-51.

[6] Ajay K. S.; Gaurang V., "A Study of Reduced Beam Section Profiles using Finite Element Analysis", Journal of Mechanical and Civil Engineering, 2013, pp. 01-06

[7] Ajay K. S.; Gaurang V., "Study of Steel Moment Connection with and without Reduced Beam Section", Case Studies in Structural Engineering, 2013, pp. 26-31

[8] AISC (2005a), ANSI/AISC 341-05. "Seismic Provisions for Structural Steel Buildings", American Institute of Steel Construction, Chicago, IL. 2005.

[9] AISC (2005b), ANSI/AISC 358-05. "Prequalified Connections for Special and Intermediate Steel Moment Frames for Seismic Applications including Supplement No.1", American Institute of Steel Construction, Chicago, IL. 2005. 
Tabel 5. Nilai Tegangan-Regangan Plastis Beton akibat Gaya Tekan

\begin{tabular}{ccc}
\hline $\begin{array}{c}\text { Stress } \\
(\mathbf{M P a})\end{array}$ & Strain & $\begin{array}{c}\text { Plastic } \\
\text { Strain }\end{array}$ \\
\hline 0.000 & 0.000 & \\
9.255 & 0.000 & 0.136 \\
16.288 & 0.001 & 0.273 \\
21.524 & 0.001 & 0.409 \\
25.284 & 0.001 & 0.545 \\
27.820 & 0.002 & 0.682 \\
29.326 & 0.002 & 0.818 \\
30.000 & 0.002 & 1.000 \\
29.848 & 0.002 & 1.091 \\
29.092 & 0.003 & 1.227 \\
27.779 & 0.003 & 1.364 \\
25.978 & 0.003 & 1.500 \\
24.536 & 0.004 & 1.591 \\
\hline
\end{tabular}

Tabel 6. Nilai Tegangan-Regangan Plastis Beton akibat Gaya Tarik

\begin{tabular}{ccc}
\hline $\begin{array}{c}\text { Stress } \\
(\mathbf{M P a})\end{array}$ & Strain & $\begin{array}{c}\text { Plastic } \\
\text { Strain }\end{array}$ \\
\hline 0.000 & 0.000000 & \\
& & \\
3.412 & 0.000123 & 0.00000 \\
2.877 & 0.000173 & 0.00005 \\
2.817 & 0.000223 & 0.00010 \\
2.766 & 0.000273 & 0.00015 \\
2.721 & 0.000323 & 0.00020 \\
2.680 & 0.000373 & 0.00025 \\
2.643 & 0.000423 & 0.00030 \\
2.610 & 0.000473 & 0.00035 \\
2.578 & 0.000523 & 0.00040 \\
2.549 & 0.000573 & 0.00045 \\
\hline
\end{tabular}

Tabel 7 Beban Dorong yang Digunakan

\begin{tabular}{cc}
\hline Step & $\begin{array}{c}\text { Beban } \\
(\mathbf{k N})\end{array}$ \\
\hline 1 & $10^{4}$ \\
2 & $10^{5}$ \\
3 & $5 \times 10^{5}$ \\
4 & $10^{6}$ \\
5 & $1.5 \times 10^{6}$ \\
6 & $2 \times 10^{6}$ \\
\hline
\end{tabular}

[10] AISC (2005c), ANSI/AISC 360-05. "Specification for Structural Steel Buildings", American Institute of Steel Construction, Chicago, IL. 2005.

[11] AISC Steel Design Guide Series-13, Stiffenening of Wide-Flange Columns at Moment Connections; Wind and Seismic Applications, American Institute of Steel Construction, Inc., Chicago, IL. 1999.

[12] Khanouki M. M. A.; Shariati M., "Investigation of Through Beam Connection to Concrete Filled
Circular Steel Tube (CFST) Column", Journal of Constructional Research, 2016, pp. 144-162.

[13] SNI-2847-2013, Persyaratan Beton Struktural untuk Bangunan Gedung. Indonesia, Badan Standarisasi Nasional.

[14] Jankowiak T.; Lodygowski T., "Identification od Parameters of Concrete Damage Plasticity Constitutive Model", Foundation of Civil and Environmental Engineering, 2005, No. 6. 